\title{
ELEGENDO MULHERES - IDEOLOGIA PARTIDÁRIA, FEMINISMO E INCLUSÃO DE MULHERES NA POLÍTICA ${ }^{12}$
}

Larissa Peixoto Vale Gomes ${ }^{3}$

\begin{abstract}
Resumo: Este artigo foca na relação entre candidatas e partidos, buscando como a ideologia partidária e o feminismo podem estruturar estes relacionamentos. Em um survey com 81 candidatas à Assembleia Legislativa de Minas Gerais em 2010, as respondentes se sentem negligenciadas e acreditam que isso tem um efeito negativo considerável sobre suas chances de sucesso, independentemente da ideologia do partido. Entrevistas semiestruturadas com três presidentes partidários estaduais de Minas Gerais (representando esquerda, centro e direita) demonstram que a retórica partidária pode ser bastante diferente, mas que ações internas diferem apenas ligeiramente. $\mathrm{O}$ estudo busca apresentar a percepção das candidatas sobre sua presença em seus partidos, e como lideranças estaduais de três partidos veem a presença feminina e a inclusão das mulheres na política. Essa pesquisa corrobora estudos prévios com dados novos, e apresenta novos conhecimentos ao campo de gênero e política.
\end{abstract}

Palavras-chave: ALMG, candidatas, ideologia, partidos, sub-representação.

Abstract: This article focuses on the relationship between female candidates and political parties, in order to understand how party ideology and feminism can structure these relationships. In a survey with 81 candidates to the Legislative Assembly of Minas Gerais in 2010, respondents state that feel neglected and believe that this has a considerable negative effect on their chances, regardless their parties' ideology. Semi-structured interviews with three party presidents of state chapters in Minas Gerais (representing left, center, and right) demonstrate that party rhetoric can be very different, but actions vary only slightly. The study brings to the fore the candidates' perception on their presence within their parties, and how state leaders perceive female presence and the inclusion of women in politics. This research corroborates previous studies with new data, and brings new information to the field of gender and politics.

Key-words: ALMG, female candidates, ideology, parties, underrepresentation

Resumen: Este artículo se centra en la relación entre candidatas y partidos, buscando cómo la ideología del partido y el feminismo pueden estructurar estas relaciones. Utilizando una encuesta de 81 candidatas a la Asamblea Legislativa de Minas Gerais en 2010, las encuestadas responden que se sienten abandonadas y creen que esto tiene un efecto negativo considerable sobre sus posibilidades de éxito, sin importar la ideología del partido. Entrevistas semiestructuradas con presidentes de tres partidos en Minas Gerais (representando a la izquierda, centro y derecha) muestran que la retórica partidista puede ser muy diferente, pero las acciones internas difieren sólo ligeramente. El estudio tiene como objetivo presentar la percepción de las candidatas acerca de su presencia en sus partidos, y como líderes de partidos ven la presencia de las mujeres y la inclusión de las mujeres en la política. Esta investigación corrobora estudios previos con nuevos datos, y presenta nuevos conocimientos para el campo de género y política.

Palabras-clave: ALMG, candidatas, ideología, partidos, subrepresentación

\section{Esquerda-centro-direita e inclusão da mulher}

A associação de mulheres a certos campos ideológicos é algo que vem sido debatido desde a inclusão de mulheres na política. Os primeiros estudos dedicados a avaliar a posição política das mulheres as colocaram na direita do espectro ideológico, enquanto estudos mais recentes apontam para uma maior presença feminina na esquerda (INGLEHART, 2005). No entanto, mulheres não são um grupo homogêneo, criando espaço para múltiplas demandas e formas de atingir resultados (PHILLIPS, 1995; DAHLERUP, 2006; BERNAUER et al., 2015). Gênero é uma variável política digna de consideração, mas não se deve presumir que mulheres defendem a mesma agenda (CELIS e CHILDS, 2012) ou mesmo que se relacionem aos seus partidos da mesma forma. Dessa forma, o objetivo deste artigo é investigar a relação entre candidatas e seus partidos, levando em conta a posição partidária no espectro ideológico. O estudo apresentado aqui foca nas candidatas à Assembleia Legislativa de Minas Gerais em 2010, e em três partidos representando os campos ideológicos (respectiva-

\footnotetext{
${ }^{1}$ Uma versão deste artigo foi apresentada no V Seminário Discente do Departamento de Ciência Política da UFMG (2015) e aceita para o 10o Encontro da Associação Brasileira de Ciência Política (2016).

${ }^{2}$ A autora gostaria de agradecer os valiosos comentários de Iris Gomes, Daniela Rezende e Ana Karruz, assim como o/a parecerista anônimo.
}

${ }^{3}$ Doutoranda em Ciência Política pela UFMG 
mente, Partido dos Trabalhadores, Partido Popular Socialista, e Partido da Social Democracia Brasileira).

O espectro ideológico "esquerda-direita” começou na Revolução Francesa, e se sustenta até hoje numa progressão de "vanguarda-conservadorismo". Enquanto as propostas associadas com cada posição variam de acordo com contextos históricos, este significados essenciais permanecem (BOBBIO, 1996). Ademais, o posicionamento é sujeito à perspectiva de quem o faz: alguém da esquerda pode julgar que uma pessoa ou partido é de centro ou de direita, ainda que não o sejam. Ele identifica a direita com conservadorismo e a esquerda com progressismo que, historicamente, é associado com movimentos de inclusão política (ibid., p. 54). Bobbio continua, identificando o objetivo igualitário com a ideologia de esquerda, observando que este não é um simplório "todos recebem de forma idêntica", mas que todos recebem "de acordo com suas necessidades. Sendo assim, a direita não busca a desigualdade, mas tem menos interesse na igualdade, objetivando a liberdade dos indivíduos da coerção estatal (DWORKIN, 2005; SKINNER, 1999). A esquerda, por sua vez, reteve os aspectos sociais advogados pelo socialismo, ainda que não mais advogasse pelo sistema. ${ }^{4}$

A questão "Estado-mercado" tem sido central à divisão ideológica em tempos recentes, apesar estar se fragilizando (CARMINES et al, 2012; SCHOLZ e ZUELL, 2012; TAROUCO e MADEIRA, 2013). Não mais se discute o tipo de Estado, comunista ou capitalista, mas quais os papéis que o Estado e o mercado devem tomar na sociedade (WALZER, 2004). A questão do escopo da intervenção estatal tem sido central, seja na regulação do mercado ou estabelecimento de leis que regulam a vida em sociedade. O surgimento de novos partidos como o Podemos, na Espanha, e o Syriza, na Grécia, aponta para novas possibilidades de ressignificação do espectro ideológico. No entanto, isso não indica o fim do uso de esquerda-centro-direita, e sim a incorporação de novas questões enquanto significados antigos caem em desuso. Gunther, Montero e Puhle (2007), ao pesquisarem a associação de valores às posições ideológicas tradicionais, demonstram que o eleitorado faz esta distinção, de forma a facilitar escolhas eleitorais.

Com relação à inclusão das mulheres, o argumento entre igualdade de oportunidade e igualdade de resultado também se associa ao espectro ideológico. Prezando pela meritocracia, formalidade das regras, e esforço individual, o conceito de igualdade de oportunidade se aproxima à pauta da direita e do liberalismo. Aqui, essa direita representa um pensamento conservador em seu sentido literal e individualista, afirmando que desde que barreiras formais, leis, garantam o acesso de todas e todos a se candidatarem, mulheres estão efetivamente inclusas no processo político. A associação entre a teoria liberal e a direita ideológica deriva-se do individualismo e do minimalismo abarcados por ambas (KYMILICKA, 1995).

O conceito de igualdade de resultado se aproxima a pautas de esquerda de inclusão ainda que sejam necessárias medidas afirmativas (PHILLIPS, 2004). Mais igualdade significa menos liberdade, pois existem mais restrições sobre o que se pode ou não fazer de forma a não interferir com os direitos de outros. Partidos de esquerda tendem a favorecer o uso destas ações afirmativas, enquanto partidos de direita as evitam ou as incorporam quando há um "efeito contágio" a partir da aceitação por suas filiadas e pela sociedade que são medidas necessárias (DAHLERUP e FREIDENVALL, 2009, p. 45).

Phillips (2004) argumenta que a igualdade de oportunidade, de fato, não gera resultados aleatórios. Se o fizesse, as casas legislativas seriam mais diversas. Oportunidade não é igualmente distribuída e gera distorções. Obstáculos culturais e estruturais permanecem, esvaziando o conteúdo da lei. Phillips propõe, então, não uma oposição entre igualdade de oportunidade e igualdade de resultado, mas seu uso complementar, com a última sendo uma forma de avaliar a primeira. Assim, a igualdade de resultados é a expectativa razoável de não ter o caminho impedido por restrições externas e chegar ao objetivo final sem enfrentar essas restrições.

\footnotetext{
${ }^{4}$ Esta é, claro, uma generalização feita por Bobbio. São vários os partido de esquerda, mesmo no Brasil, que se declaram socialistas. No entanto, a defesa do sistema tem perdido força mesmo entre esses atores que têm, por sua vez, buscado incorporar ideais socialistas dentro do sistema
} 
Ela é comprovada na aleatoriedade dos resultados, na falta de previsibilidade sobre qual grupo será dominante. Este argumento costuma ser usado quando são realizadas ações afirmativas, muitas vezes por partidos da esquerda, que se propõem a remover os obstáculos estruturais identificados, mas velados (WALZER, 2004). É importante notar que este debate se restringe a medidas de inclusão de mulheres no processo político, não discutindo pautas políticas. Ademais, a associação entre os diferentes conceitos de igualdade e a associação destes com o espectro ideológico "esquerda-direita" é teorizado e precisa ser corroborado empiricamente.

No Brasil, o significado-chave do espectro ideológico se sustenta, tanto para representantes quanto para votantes (SANTOS, 2008) ainda que não haja alta identificação partidária (VEIGA, 2007). Tarouco e Madeira (2013, p. 159) sustentam que o campo ideológico-partidário brasileiro é bidimensional, com o espectro esquerda-direita perpassado pelo progressista-conservador, ao invés de se confundir com ele. Zucco e Lauderdale (2011), afirmam que nas votações em Congresso existe também uma divisão governo versus oposição. Ideologia partidária, portanto, tem dimensões formativas que são econômicas e socioculturais (CARMINES et al., 2012).

A democracia brasileira ainda é recente e as regras formais ainda não estão firmadas em prática. Agremiações se encontram em fluxo, com partidos sendo criados constantemente, com o sistema partidário ainda em processo de estabilização de suas atuações. Apesar de existir um consenso na academia e também de senso comum sobre o que configura, atualmente, esquerda, centro e direita, isso não quer dizer que essas determinações são fixas ou aplicáveis ao Brasil e a essa pesquisa. Num país federalista, ideologia partidária pode funcionar de forma diferente nos níveis estaduais e municipais, e o nível federal tem sido o mais estudado. Conhecimento sobre o posicionamento ideológico de um partido pode vir de dois tipos de pesquisa: da percepção de seus eleitos, que tem sido mais comum; ou indiretamente, através de votações nominais, manifestos partidários ou outras ações similares. Isso dito, também se deve lembrar que ainda permanecem resquícios coronelistas e personalistas na política brasileira. São muitos os partidos chamados de "fisiológicos" ou "legenda de aluguel", que não possuem programa ou mesmo posicionamentos (SAMUELS, 1997). Essa característica pode, por vezes, impedir a interpretação adequada do posicionamento do partido na escala ideológica. Isso fica claro na análise dos dois principais partidos brasileiros, o Partido dos Trabalhadores (PT) e o Partido da Social Democracia Brasileira (PSDB). Esses partidos ocupam posições de destaque na política nacional e local por polarizarem as eleições presidenciais desde 1994 (MELO, 2010). Eles efetivamente criaram o "atalho" necessário para que o eleitorado identifique o partido imediatamente (LEONI, 2002; POWER e ZUCCO, 2009). Pesquisas (LEONI, 2002; SANTOS, 2008; POWER e ZUCCO, 2009; ZUCCO, 2009; CEL, 2005; 2010) mostram que os três partidos estudados na pesquisa apresentada aqui, se encontram, atualmente, em locais diferentes do espectro ideológico, permitindo uma análise da esquerda, do centro e da direita sobre a inclusão da mulher na política.

Inglehart e Norris (2005) posicionam o Brasil em um contexto transicional, sendo um país ainda religioso, com uma democracia recente e em uma circunstância de desigualdade social. A combinação desses fatores não permite a certeza de causalidade (a maioria dos países religiosos e com desigualdade social em níveis similares tende observar mais mulheres à direita), mas as mulheres brasileiras tendem a ser de esquerda, superando quase todos os países estudados, incluindo tradicionalistas e seculares/industrializados..$^{5}$ Os autores também afirmam que a diferença ideológica entre mulheres (de esquerda) e homens (de direita) é maior em países mais pobres e em processo de transição.

Pesquisas nacionais com elites políticas mostram a presença feminina mais acentuada na esquerda partidária. O Centro Feminista de Estudos eAssessoria (2009) mostra que 67\% das parlamentares se posicionam à esquerda contra $50 \%$ dos homens ( $27 \%$ das mulheres se colocaram na direita, contra $39 \%$ dos homens). As mulheres 
se mostram mais favoráveis em relação a medidas que aumentem sua presença: 74\% acreditam que deveria haver punição se as cotas eleitorais não são cumpridas; $27 \%$ dos homens escolheram a mesma opção. Deve-se considerar a possibilidade que mulheres podem concordar com seus partidos em certos pontos, e discordar em outros.

Pode ser observada uma diferença de tratamento das mulheres e de questões importantes para elas dentro do espectro "esquerda-direita". Considerando que partidos de esquerda tendem a ter uma presença feminina maior, eles também tendem a dar mais atenção a assuntos que têm sido usados como balizas para identificar atuação voltada para os interesses e necessidades das mulheres, que acabam como congruentes com a pauta feminista. Celis e Childs (2012) apontam para os interesses de mulheres conservadoras e a miríade de pautas que interessam a mulheres de todos os setores da sociedade. Enquanto questões de interesse para mulheres podem ser encontradas em programas partidários, sites e discursos de alguns representantes, não existe muito em termos de avaliação científica da penetração de assuntos importantes para as mulheres no cotidiano partidário.

\section{Objetivos e metodologia da pesquisa}

A metodologia consistiu de dois eixos: o primeiro, um survey com as candidatas à deputada estadual de Minas Gerais (2010); o segundo, entrevistas semiestruturadas com três presidentes estaduais de partidos relevantes no cenário estadual e representativos dos pontos principais do espectro ideológico foram selecionados para a realização de entrevistas semiestruturadas com seus dirigentes: o Partido dos Trabalhadores ${ }^{6}$, o Partido Popular Socialista ${ }^{7}$ e o Partido da Social Democracia Brasileira ${ }^{8}$. Tentou-se contatar todas as candidatas, mas a relutância de certos partidos e a dificuldade em encontrá-las de forma independente determinou o tamanho da amostra. Das 140 candidatas $^{9}$, 81 responderam o survey (57\%), compondo uma amostra de 14 partidos. Três O survey e as entrevistas agem como contrapontos, demonstrando a posição de candidatas, a linha de frente dos partidos, e das lideranças partidárias.

Exceto pelo Partido Socialista dos Trabalhadores Unificado (PSTU), que teve $40 \%$ de candidatas, o PPS foi o partido que mais se aproximou da cota eleitoral de gênero, que determina que as listas partidárias devem ser compostas por 30\% de pessoas de um dos sexos, com 28,8\% (19 candidatas). O PT teve $19 \%$ de candidatas (15, no total) e o PSDB teve $8 \%$ (2 candidatas). Considerando a votação das candidatas, o PT teve o maior percentual de votos, com 20,8\%, o PPS ficou em segundo lugar com 14,1\% e o PSDB obteve 7,3\% dos votos. Cada um desses partidos possui nuances e detalhes, tanto em sua história quanto no momento da pesquisa e podem se encaixar ou não em questões ao longo do eixo esquerda-direita. Para os efeitos dessa pesquisa, eles são vistos em sua forma agregada e com relação somente à questão da inclusão das mulheres na política. Ou seja, busca-se ver se a inclusão das mulheres é um tópico que perpassa linhas ideológicas ou se os partidos se posicionam de forma diferenciada de acordo com ideologia.

${ }^{6}$ O PT é um dos partidos mais identificados com a esquerda, ainda que tenha se movimentado para o centro nos últimos anos. Além disso, também é um dos partidos mais identificados com o feminismo e com a inclusão política de minorias (o PT usa política de cotas internas há muitos anos e recentemente ampliou-as para $50 \%$ ).

${ }^{7}$ O PPS, ex-Partido Comunista Brasileiro, se movimentou da extrema-esquerda até o centro sendo por vezes identificado como centro-esquerda e por vezes identificado como centro-direita. Como o PPS tem uma presidenta estadual que tem um histórico de atuação feminista, existe um contraponto interessante a ser oferecido entre as entrevistas com um homem de um partido de esquerda e uma mulher, feminista, de um partido de centro.

${ }^{8}$ O PSDB, partido que começou como uma ala à esquerda no Partido do Movimento Democrático Brasileiro (PMDB) caminhou, desde o governo de FHC e a aliança com o Partido da Frente Liberal (agora, Democratas), para a direita. Atualmente, o PSDB tem sido identificado como centro-direita, por vezes, centro. Para as eleições de 2010 para a Assembleia Legislativa de Minas Gerais, o partido apresentou duas candidatas.

9 A ALMG possui 77 assentos. Foram 140 candidatas e 803 candidatos, totalizando 943 candidaturas (14,86\% de candidaturas femininas). 
As entrevistas seguiram um roteiro semiestruturado com perguntas em quatro eixos: recrutamento, capacitação, participação no partido e apoio (financeiro, publicitário, marketing, eventos). O roteiro de perguntas não foi específico à campanha de 2010, permitindo um insight sobre a posição dos entrevistados, seu entendimento sobre a atuação do partido em relação à participação feminina e seu conhecimento sobre ferramentas de inclusão. Partidos são os principais atores que protegem os "portões de entrada" da política, e seus dirigentes, mesmo locais, têm o poder de atuar de forma a provocar mudança. Por isso, o método qualitativo permite uma pesquisa mais detalhada sobre esses processos (ALLEN, 2013; HUGHES e PAXTON, 2008; LAWLESS e FOX, 2010). Aqui, o objetivo era conhecer a posição oficial dos partidos e as ações tomadas no nível pesquisado, sendo imperativo, portanto, que o presidente estadual respondesse as questões.

\section{Resultados e discussão}

\section{A. Resultados do survey}

O perfil das candidatas entrevistadas é congruente com a maioria das pesquisas e hipóteses sobre mulheres na política institucional: 85,2\% residiam na região metropolitana de Belo Horizonte; 51,9\% estavam casadas ou em união civil; $71,6 \%$ são mães; $48,1 \%$ têm ensino superior completo, com $21 \%$ sendo professoras (em todos os níveis de ensino); a renda mensal de 71,6\% se encontrava na faixa de um a dez salários míni$\operatorname{mos}^{10} ; 51,8 \%$ têm entre 44 e 56 anos.

\section{Sobre ideologia partidária}

Somente alguns partidos se dispuseram a fornecer os nomes e contatos das candidatas. Estes foram divididos em três campos ideológicos, levando em conta, principalmente, Zucco e Lauderdale (2011), Zucco (2009), Power e Zucco (2009) e CEL (2003; 2007). Tem-se, entre as entrevistadas, $30,9 \%$ à esquerda, $50,6 \%$ ao centro e $18,5 \%$ à direita. A maioria dos partidos que se recusou a participar eram de direita, algo que dificultou equilíbrio entre os campos ideológicos. ${ }^{11}$

Foi pedido às entrevistadas que se posicionassem em uma escala de $1 \mathrm{a} 5$, respectivamente, da esquerda à direita. A escala foi escolhida por permitir uma opção exata ao centro. Escolheu-se, objetivando clareza na apresentação dos dados, apresentar uma escala com três opções, entre esquerda, centro, e direita. Assim, as respostas foram agrupadas em esquerda (posições 1 e 2), centro (posição 3) e direita (posições 4 e 5). A Tabela 1 apresenta o posicionamento ideológico das candidatas de acordo com a academia, seu autoposicionamento, e como posicionaram seus partidos na escala. Somente uma entrevistada se autoposicionou na opção 5, a mais à direita da escala. Nenhuma escolheu essa posição para seu partido.

\section{Tabela 1: Comparação entre o posicionamento das entrevistadas pelo padrão acadêmico, seu autoposicionamento e como} posicionam seus partidos

\footnotetext{
${ }^{10}$ À época, o salário mínimo era $\mathrm{R} \$ 545,00$.

${ }^{11} \mathrm{O}$ agrupamento se deu da seguinte forma: na esquerda ficaram o Partido Comunista do Brasil, o Partido Socialista Brasileiro, Partido Socialismo e Liberdade, Partido Socialista dos Trabalhadores Unificado e o Partido dos Trabalhadores; no centro ficaram o Partido Democrático Trabalhista, o Partido do Movimento Democrático Brasileiro, o Partido Popular Socialista e o Partido Verde; na direita ficaram o Democratas, o Partido Republicano Brasileiro, o Partido da Social Democracia Brasileira, o Partido Trabalhista do Brasil e o Partido Trabalhista Brasileiro.
} 


\begin{tabular}{|l|l|l|l|l|l|}
\hline \hline & Esquerda & Centro & Direita & $\begin{array}{l}\text { Não sabe/Não } \\
\text { respondeu }\end{array}$ & Total \\
\hline $\begin{array}{l}\text { Posicionamento das entrevistadas de } \\
\text { acordo com a academia }\end{array}$ & $25(30,9 \%)$ & $41(50,6 \%)$ & $15(18,5 \%)$ & - & $81(100 \%)$ \\
\hline Autoposicionamento & $38(46,9 \%)$ & $25(30,9 \%)$ & $5(6,2 \%)$ & $13(16 \%)$ & $81(100 \%)$ \\
\hline $\begin{array}{l}\text { Posicionamento do próprio partido } \\
\text { pelas entrevistadas }\end{array}$ & $36(44,5 \%)$ & $23(28,4 \%)$ & $10(12,3 \%)$ & $12(14,8 \%)$ & $81(100 \%)$ \\
\hline
\end{tabular}

Fonte: a autora, a partir dos dados coletados para a pesquisa.

As entrevistadas mostraram coerência interna, algo que pode ser observado pelas porcentagens similares entre o autoposicionamento e o posicionamento do partido, com a exceção do autoposicionamento à direita. Nota-se uma discrepância entre o que é sabido pela academia e o que é percebido pelas entrevistadas. Os únicos campos que viram crescimento foram o da esquerda e da não-resposta. A maior parte dessa pulverização parece vir do centro. Candidatas de partidos de centro podem ter maior fluidez na identificação ideológica, tendo em vista a moderação ou não-tomada de posição de seus partidos. Sendo assim, é esperado que candidatas que se identifiquem como "centro-esquerda", "centro-direita" ou, simplesmente não acatam essas divisões, não escolham o centro como sua posição ideológica. As candidatas de esquerda foram coerentes com o que é sabido sobre a construção ideológica e programática desses partidos no Brasil e não desviaram em suas respostas. No caso das candidatas da direita, observou-se, que elas se distribuíssem entre o centro, a direita e a não-resposta. Dada essa importante variação, que diminui drasticamente o número de candidatas à direita, considerou-se que o uso da interpretação da literatura sobre a quais campos ideológicos as entrevistadas pertencem fosse mais útil para os propósitos deste artigo.

As entrevistadas foram perguntadas se já tiveram cargos no partido, como diretorias, secretarias e coordenadorias, que são uma maneira de formar alianças, além de demonstrar compromisso. Lideranças têm maior facilidade em conseguir apoio às suas candidaturas, acesso à publicidade, tomada de decisão, prestígio interno e indicação para cargos no executivo. Sessenta por cento das mulheres à esquerda afirmaram que já ocuparam cargos no partido, em comparação com $31,7 \%$ do centro e $37,5 \%$ da direita. Vale apontar que não foi perguntado quais cargos e qual nível do partido estes ocupavam porque o ponto relevante era ter ocupado qualquer cargo.

O critério mais importante ao escolher o partido foi, para $48 \%$ das candidatas da esquerda, "atração pela ideologia ou pelo programa do partido"; as candidatas do centro escolheram "influência dos membros de minha família ou de amigos próximos", com 39\% das respostas; e as candidatas da direita responderam que foi "contato pessoal com os dirigentes locais do partido" (46,7\%). Vê-se, na Tabela 2, os resultado por campo ideológico e agregado. No total, $37, \%$ das candidatas escolheram seus partidos por congruência ideológica. É importante lembrar a importância de conexões pessoais, tanto para mulheres quanto para homens, para obter sucesso na política.

Tabela 2: Cruzamento entre o campo ideológico e o critério mais importante para a escolha do partido 


\begin{tabular}{|c|c|c|c|c|c|c|c|c|}
\hline \multirow{2}{*}{\multicolumn{2}{|c|}{$\begin{array}{l}\text { Influência dos mem- } \\
\text { bros de minha família } \\
\text { ou de amigos próximos }\end{array}$}} & \multicolumn{6}{|c|}{ Critério mais importante para a escolha do partido } & \multirow{3}{*}{$\begin{array}{l}\text { Total } \\
25(100 \%)\end{array}$} \\
\hline & & \multirow{2}{*}{$\begin{array}{l}\text { Contato pes- } \\
\text { soal com os di- } \\
\text { rigentes locais } \\
\text { do partido }\end{array}$} & \multirow{2}{*}{\begin{tabular}{|l|}
$\begin{array}{l}\text { Atração pela } \\
\text { ideologia ou } \\
\text { pelo programa } \\
\text { do partido }\end{array}$ \\
$5(20,0 \%)$
\end{tabular}} & \multirow{2}{*}{\begin{tabular}{|l|}
$\begin{array}{l}\text { Maior chance } \\
\text { eleitoral que } \\
\text { o partido } \\
\text { proporciona }\end{array}$ \\
$12(48,0 \%)$ \\
\end{tabular}} & \multirow{2}{*}{\begin{tabular}{|l|}
$\begin{array}{l}\text { Força do par- } \\
\text { tido na região } \\
\text { do estado }\end{array}$ \\
$1(4,0 \%)$ \\
\end{tabular}} & \multirow{2}{*}{\begin{tabular}{|l}
$\begin{array}{l}\text { Não re- } \\
\text { spondeu }\end{array}$ \\
$0(0,0 \%)$
\end{tabular}} & \multirow{2}{*}{\begin{tabular}{|l|} 
\\
$0(0,0 \%)$ \\
\end{tabular}} & \\
\hline Campo & Esquerda & & & & & & & \\
\hline & Centro & $16(39,0 \%)$ & $9(22,0 \%)$ & $12(29,3 \%)$ & $2(4,9 \%)$ & $2(4,9 \%)$ & $0(0,0 \%)$ & $41(100 \%)$ \\
\hline & Direita & $1(6,7 \%)$ & $7(46,7 \%)$ & $6(40,0 \%)$ & $0(0,0 \%)$ & $0(0,0 \%)$ & $1(6,7 \%)$ & $15(100 \%$ \\
\hline \multicolumn{2}{|l|}{ Total } & $24(29,6 \%)$ & $21(25,9 \%)$ & $30(37,0 \%)$ & $3(3,7 \%)$ & $2(2,5 \%)$ & $1(1,2 \%)$ & $81(100 \%)$ \\
\hline
\end{tabular}

Fonte: a autora, a partir dos dados coletados para a pesquisa

Estas respostas, quando comparadas com o autoposicionamento na escala ideológica, mostram um retrato interessante sobre a conexão entre as candidatas, o partido e a ideologia: para as candidatas da esquerda, é importante que seu partido professe a mesma ideologia que ela mesma; para as candidatas do centro, é importante que tenham conexões pessoais dentro do partido antes da filiação, algo que ajuda a explicar a forte dispersão no uso do espectro ideológico e o alto uso da não-resposta por essas candidatas. As candidatas da direita se dividiram quase igualmente entre conexões pessoais e proximidade ideológica.

Sobre se pretendem continuar filiadas ao partido, a maioria das candidatas respondeu que sim: na esquerda, apenas uma respondeu que iria trocar de partido; no centro, 70,7\% responderam que iriam permanecer, com $22 \%$ de indecisas (7,3\% pretendiam trocar de partido); e na direita foram $78,6 \%$ respostas afirmativas e $21,4 \%$ indecisas (houve uma não-resposta). As respostas das candidatas de esquerda indicam maior proximidade com o partido e comprometimento com objetivos a longo prazo, enquanto as respostas das candidatas de centro e direita aparentam ser mais flexíveis com possíveis mudanças.

\section{Sobre feminismo e ideologia partidária}

Na questão A senhora se considera feminista?, 56,8\% responderam que sim, 33,3\% responderam mais ou menos e 9,9\% responderam que não. A autodeclaração é uma forma de aferir o entendimento das entrevistadas sobre o feminismo. Por isso, a questão seguinte perguntou o que elas entendem por feminismo. Espera-se, ao usar ambas questões, dois possíveis resultados: que sejam similares, denotando coerência e entendimento comparáveis; que apresentam uma grande diferença, denotando desconhecimento sobre o conceito. Não se pede, no entanto, que elas advoguem por alguma das opções, ou seja, é possível se declarar não-feminista e selecionar a opção correta para definir o feminismo. Dessa forma, quando há uma diferença entre a quantidade de mulheres que entende o conceito, mas não se declarou feminista na questão anterior, é possível que esteja em ação um preconceito com relação ao rótulo "feminista". Este foi o caso aqui, já que $71,6 \%$ escolheram "lutar por direitos ou pela igualdade de direitos entre homens e mulheres". ${ }^{12}$ Essa discrepância também pode ser indicativa de desconhecimento sobre feminismo, assim como uma atitude a favor do "politicamente correto".

\footnotetext{
${ }^{12}$ As outras opções foram: ser melhor que os homens (1,2\%); ganhar o mesmo salário ou ter os mesmos empregos que os homens (3,7\%); não depender de um homem financeiramente (2,5\%); ser diferente e não precisar de aprovação de ninguém (8,6\%); ser uma boa mãe/filha/esposa $(7,4 \%)$; comandar a própria casa, mesmo casada (1,2\%); ser feminina e vaidosa (1,2\%); não respondeu $(1,2 \%)$.
} 
Ao cruzar as variáveis sobre o posicionamento ideológico das candidatas como é visto pela literatura com a autodeclaração sobre feminismo, observa-se que em todos os campos ideológicos a maioria das entrevistadas se identifica como feminista: $60 \%, 53,7 \%, 60 \%$, respectivamente. ${ }^{13}$ Os resultados completos podem ser vistos na tabela abaixo.

\begin{tabular}{|l|l|r|r|r|r|}
\hline \multicolumn{2}{|l|}{ Tabela 3: Cruzamento entre campo ideológico e autodeclaração de feminismo } \\
\cline { 3 - 6 } & \multicolumn{1}{|c|}{ A senhora se considera feminista? } & \multicolumn{1}{c|}{ Total } \\
\cline { 3 - 6 } & & & \multicolumn{1}{c|}{ Sim } & Mais ou menos & \\
\hline \multirow{3}{*}{ Campo ideológico } & Esquerda & $2(8,0 \%)$ & $15(60,0 \%)$ & $8(32,0 \%)$ & $25(100 \%)$ \\
\cline { 2 - 6 } & Centro & $6(14,6 \%)$ & $22(53,7 \%)$ & $13(31,7 \%)$ & $41(100 \%)$ \\
\cline { 2 - 6 } & Direita & $0(0,0 \%)$ & $9(60,0 \%)$ & $6(40,0 \%)$ & $15(100 \%)$ \\
\hline \multirow{2}{*}{ Total } & $8(9,9 \%)$ & $46(56,8 \%)$ & $27(33,3 \%)$ & $81(100 \%)$ \\
\hline
\end{tabular}

Fonte: a autora, a partir dos dados coletados para a pesquisa.

Quando perguntadas qual era, na opinião delas, a principal razão de existirem poucas candidatas para cargos legislativos, 48,1\% responderam que era por falta de apoio da sociedade; 13,6\% identificaram falta de apoio do partido e $11,1 \%$ falaram que as mulheres têm menos tempo livre que os homens. Onze $(13,6 \%)$ falaram que a maioria das mulheres gosta de política menos que os homens e uma afirmou que a maioria das mulheres não tem habilidade para política. Dez (12,3\%) responderam que era outra opção além das oferecidas e, em geral, sugeriram questões culturais e estruturais, assim como desilusão com a política brasileira. Das mulheres que se identificam como feministas, 54,3\% acreditam que a falta de apoio da sociedade é o maior obstáculo. Esta também foi a opção mais selecionada em todos os campos ideológicos.

A última pergunta diretamente ligada ao feminismo questiona a opinião das entrevistadas sobre qual deve ser o lugar das questões de gênero em um mandato exercido por uma mulher: 33,3\% responderam que deve ocupar o centro da atividade legislativa; 53,1\% afirmaram que deve ser uma questão importante, mas não deve ofuscar outras questões; $11,1 \%$ afirmaram que ocupa um lugar secundário. Somente uma afirmou que não é uma preocupação e uma não respondeu. Das 27 entrevistadas que afirmaram que as questões de gênero devem ocupar o centro da atividade legislativa de uma mulher, 25 (92,6\%) se autodeclararam feministas. Observando os campos ideológicos, as candidatas de direita (46,7\%) afirmaram que deve ocupar o centro da atividade legislativa, enquanto as candidatas de esquerda $(60,0 \%)$ e centro $(56,1 \%)$ afirmaram que é uma das questões importantes. Levando em consideração o tipo de relacionamento que candidatas de esquerda têm com seus partidos, o compromisso de longo prazo com a ideologia e o programa, pode-se sugerir que estas candidatas veem a questão de gênero como importante entre os outros pontos defendidos pelo partido. É também possível que as candidatas de direita se vejam como atuando em prol das mulheres, algo que faz sentido considerando que o relacionamento com o partido é menos estável e que partidos de direita tendem a ser menos programáticos.

No caso apresentado aqui, as atitudes feministas são suprapartidárias. A maioria das entrevistadas, independentemente do campo ideológico, se autodeclarou feminista (ou "mais ou menos" feminista), reconheceu corretamente o conceito básico de feminismo, identificou a falta de apoio da sociedade e a importância de legislar para as mulheres. É importante lembrar que elas foram indagadas somente sobre inclusão da mulher e sobre feminismo enquanto a defesa da igualdade entre os gêneros, sem identificar como atingir esta igualdade.

Atuação dentro do partido e apoio partidário na campanha

${ }^{13}$ Os resultados são similares se é considerada a auto-classificação no espectro ideológico, com a exceção das não-respondentes, que obteve maioria de respostas "mais ou menos" feminista $(53,8 \%)$. 
Às entrevistadas foram feitas várias perguntas14 sobre qual a frequência e o tipo de atuação que têm dentro do partido. Assim como ter cargo no partido, fazer parte do cotidiano partidário é extremamente importante para formação de alianças. Partidos brasileiros possuem a vantagem da representação proporcional com lista aberta, o que significa que não é necessário se comprometer a um programa ou aos candidatos e candidatas apresentados. Não se defende, aqui, que todos os candidatos tenham vantagens sobre as candidatas no quesito do apoio partidário. Vagas são preenchidas de forma a facilitar a vitória do partido e suas lideranças, os poucos candidatos e candidatas que os partidos se empenham para garantir a vitória. No entanto, entende-se que a maior parte das lideranças partidárias é composta por homens; que inúmeros candidatos, mas quase todas as candidatas estão ali para facilitar e garantir a eleição destas lideranças. O que é debatido aqui é a percepção que as candidatas pesquisadas têm sobre como o partido se relaciona com elas.

Buscou-se aferir se a participação era constante e se elas sentem que participam de forma igualitária aos homens. Nota-se a existência de receio ou cautela: 40,7\% das entrevistadas responderam que não têm o hábito de falar em reuniões partidárias. A maioria das entrevistadas de centro (48,8\%) e de direita $(53,3 \%)$ escolheram essa opção, contra $20 \%$ das de esquerda (Tabela 4). Por outro lado, $86,4 \%$ que afirmaram que as mulheres do partido são ativas nos encontros partidários (12,3\% responderam "mais ou menos" e uma não respondeu). A mesma porcentagem (86,4\%) identificou que existem mulheres em cargos de direção $(9,9 \%$ afirmaram que não; duas não sabiam ou não se lembravam; uma não respondeu). Ambas as variáveis não tiveram distinções extremas entre campos ideológicos.

Entre os vários obstáculos informais enfrentados pelas mulheres na política e em outras posições de liderança, encontram-se a falta de treinamento para falar em público e o desrespeito durante a fala, na forma de conversas paralelas, interrupções, e reprodução de suas falas por colegas homens. Nota-se uma distinta diferença nos campos ideológicos, com mulheres da esquerda mais propensas a participar, algo que pode ser por várias razões, como melhor capacitação, maior tempo de partido e, inclusive, a possibilidade que estes partidos deem mais espaço para a participação das mulheres tendo em vista a defesa da igualdade de gêneros proferida pela maioria deles. Nota-se que, no total, a maioria das mulheres $(49,4 \%)$ tem o hábito de falar em reuniões do partido, enquanto $40,7 \%$ não têm esse hábito. É, de fato, uma grande porcentagem de mulheres que preferem não atuar desta forma, algo interessante tendo em vista a importância da fala pública na política. É importante ressaltar que o objetivo da pergunta era perguntar sobre este tipo de atividade integrada, sem especificar reuniões de departamentos femininos.

\footnotetext{
${ }^{14}$ Tem hábito de falar em reuniões do partido?; Existem mulheres com cargos na direção do partido, excetuando o Departamento Feminino?; As mulheres do partido marcam presença e falam em reuniões, congressos e conferências do partido?; As mulheres do partido recebem a mesma atenção e respeito que os homens quando falam?; As filiadas do partido têm as mesmas vantagens, oportunidades, benefícios e poder que os filiados?; O partido realiza cursos de capacitação para as mulheres que querem ingressar na vida política; É papel do partido tomar iniciativas para facilitar a vida da filiada e candidatas?
} 


\begin{tabular}{|c|c|c|c|c|c|}
\hline \multirow{2}{*}{\multicolumn{2}{|c|}{ GOMES, Larissa Peixoto. Elegendo mulhe }} & \multicolumn{3}{|c|}{ 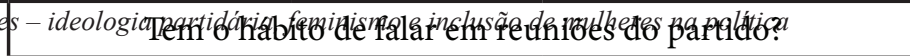 } & \multirow[t]{2}{*}{ Total } \\
\hline & & Não & $\operatorname{sim}$ & Não respondeu & \\
\hline \multirow[t]{3}{*}{ Campo ideológico } & Esquerda & $5(20,0 \%)$ & $18(72,0 \%)$ & $2(8,0 \%)$ & $25(100 \%)$ \\
\hline & Centro & $20(48,8 \%)$ & $18(43,9 \%)$ & $3(7,3 \%)$ & $41(100 \%)$ \\
\hline & Direita & $8(53,3 \%)$ & $4(26,7 \%)$ & $3(20,0 \%)$ & $15(100 \%)$ \\
\hline \multicolumn{2}{|l|}{ Total } & $33(40,7 \%)$ & $40(49,4 \%)$ & $8(9,9 \%)$ & $81(100 \%)$ \\
\hline
\end{tabular}

Fonte: a autora, a partir dos dados coletados para a pesquisa.

Sobre as ações tomadas pelos partidos em relação às mulheres: 52,5\% do total acreditam que as mulheres não recebem a mesma atenção e respeito que os homens quando falam. Destas, $68 \%$ das entrevistadas da esquerda escolheram essa opção, contra 48,8\% e 35,7\% das de centro e direita, respectivamente. As entrevistadas de direita se dividiram quase igualmente entre as opções. São muitas as possibilidades de explicação para essa diferença: maior participação pode levar a maior sensibilidade; maior conhecimento sobre táticas de inferiorização da fala de mulheres; é possível que uma socialização conservadora, de proteção ao "sexo frágil" leve os homens de centro e de direita a serem mais respeitosos. O Gráfico 1 mostra as respostas de acordo com campo ideológico.

Valores em \%. Um caso excluído (não respondeu).

Fonte: a autora, a partir dos dados coletados para a pesquisa.

Apenas 17,5\% acreditam que as filiadas recebem as mesmas oportunidades e benefícios que os filiados.

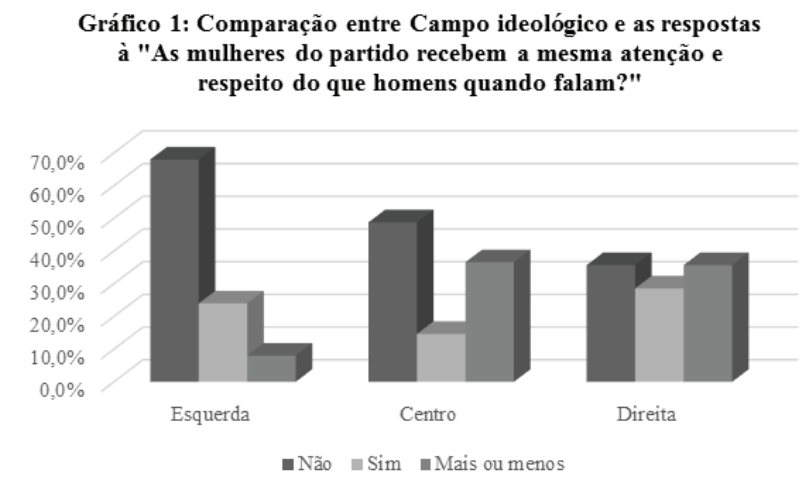

A divisão entre campos ideológicos foi similar à questão anterior: a esquerda optou por "não" (52\%), o centro escolheu "mais ou menos" (51,2\%) e a direita se dividiu quase igualmente.

Valores em \%. Um caso excluído (não respondeu).

Fonte: a autora, a partir dos dados coletados para a pesquisa.

Sobre a existência de cursos de capacitação para as mulheres que querem entrar na vida política, $61,7 \%$ afirmaram que não existem, sem grandes diferenças entre campos ideológicos. Isto é importante considerando

\section{Gráfico 2: Comparação entre Campo ideológico e as respostas à \\ "As filiadas do partido têm as mesmas vantagens, oportunidades, benefícios e poder que os filiados?"}

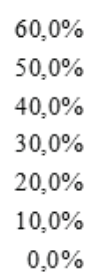

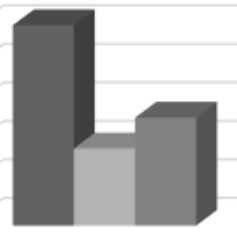

Esquerda

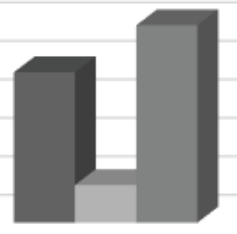

Centro

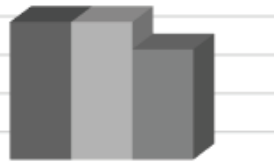

Direita

- Não $\quad$ - Sim $\quad$ Mais ou menos 
citação são indicados por organizações internacionais e pela academia como formas de inclusão das filiadas, de forma a suprir a falta de conhecimento sobre cotidiano partidário, táticas de eleição, e retórica. Eles são vistos como medidas passíveis de auxiliar candidatas sem serem ações afirmativas. Das entrevistadas, 90,1\% concorda que é papel do partido tomar iniciativas para ajudar suas filiadas e candidatas. Esses dados são congruentes com relatos e pesquisas que mostram um desinteresse dos partidos em investir nas suas filiadas e que é a falta de qualificação e de capital político que impede o avanço das mulheres na política (MIGUEL, 2003). Para 56,8\% das entrevistadas, o principal fator para ganhar uma eleição é o apoio partidário. Não houve diferença significativa entre os campos ideológicos. Isso indica que as mulheres reconhecem a importância do apoio do partido, com ferramentas de inclusão e apoio financeiro independentemente de outras posições ideológicas.

Dada a importância do apoio partidário em uma campanha e a forte opinião das entrevistadas nesse sentido, é importante expor suas respostas sobre como esse apoio se deu em 2010. ${ }^{15}$ Vale lembrar que estas respostas se referem à percepção das candidatas sobre o que elas acreditam ser o papel do partido em uma candidatura. Quase todas as respostas foram negativas: 70,4\% afirmaram não terem recebido qualquer apoio financeiro; 74,1\% receberam pouca assistência para confecção de material publicitário; 65,5\% afirmaram que candidatos com mais dinheiro ou maior potencial de votação receberam mais tempo no Horário de Propaganda Eleitoral Gratuita (16\% afirmaram que a divisão foi igualitária e 12,3\% afirmaram que os homens tiveram mais e/ou melhores espaços, 6,2\% não responderam); $82,7 \%$ afirmaram que o partido não ofereceu capacitação para as candidatas; $64,2 \%$ afirmaram que o partido não ofereceu apoio logístico (como creches ou transporte) para facilitar a presença das mulheres em eventos do partido; 60,5\% afirmaram que não receberam ajuda para montagem de eventos. Onze entrevistadas $(13,6 \%)$ afirmaram que o partido ofereceu cursos de capacitação para as candidatas em 2010. Destas, seis eram da esquerda, quatro do centro e uma da direita.

\begin{tabular}{|c|c|c|c|c|c|}
\hline & Muita & Pouca & Nenhuma & Não respondeu & Total \\
\hline Financeira & $0(0,0 \%)$ & $24(29,6 \%)$ & $57(70,4 \%)$ & $0(0,0 \%)$ & $81(100 \%)$ \\
\hline Material publicitário & $5(6,2 \%)$ & $60(74,1 \%)$ & $16(19,8 \%)$ & $0(0,0 \%)$ & $81(100 \%)$ \\
\hline Apoio logístico & $0(0,0 \%)$ & $24(29,6 \%)$ & $52(64,2 \%)$ & $5(6,1 \%)$ & $81(100 \%)$ \\
\hline Montagem de eventos & $0(0,0 \%)$ & $49(60,5 \%)$ & $31(38,3 \%)$ & $1(1,2 \%)$ & $81(100 \%)$ \\
\hline
\end{tabular}

Fonte: a autora, a partir dos dados coletados para a pesquisa.

O cruzamento das variáveis de apoio partidário com a variável Campo ideológico mostrou pouca variação, com uma ligeira tendência para apoio maior da esquerda. Ainda assim, é aparente que não há distinção ideológica com relação ao apoio às mulheres, seja este apoio material ou na forma de tratamento igualitário dentro do partido. Como dito anteriormente, partidos tendem a investir em candidatos que têm o maior poten-

\footnotetext{
${ }^{15}$ Em sua campanha em 2010, recebeu ajuda financeira do seu partido?; Em sua campanha, em 2010, recebeu ajuda para confeç̧ão de material publicitário do seu partido?; Poderia me dizer como foi a divisão do tempo no horário eleitoral?; Para a campanha de 2010, o seu partido forneceu cursos de capacitação para as candidatas?; Para a campanha de 2010, o seu partido forneceu cursos de capacitação para as candidatas?; Para a campanha de 2010, o seu partido forneceu serviços para facilitar participação (em eventos do partido), como creches e outros apoios logísticos?; O seu partido auxiliou na montagem de eventos de sua campanha?; Qual foi a principal estratégia de financiamento utilizada em sua campanha?
} 
cial para ganhar a eleição e, raramente, as mulheres se encontram nessa posição dada a falta de acesso a recursos financeiros (84\% afirmaram terem utilizado majoritariamente recursos próprios ou de familiares e amigos; somente 3,7\% afirmaram que os principais recursos financeiros vieram do partido), falta de capital simbólico e falta de redes de apoio. Sendo assim, os dados demonstram que as atuais condições não são suficientes para aumentar a eleição de mulheres para cargos legislativos e mais investimentos são necessários.

\section{B. Resultados das entrevistas semiestruturadas}

As entrevistas semiestruturadas foram feitas com três presidentes partidários do estado de Minas Gerais, a saber, do Partido dos Trabalhadores (PT), Reginaldo Lopes, do Partido Popular Socialista (PPS), Luzia Ferreira e do Partido da Social Democracia Brasileira (PSDB), Marcus Pestana. Estas foram feitas entre dezembro de 2010 e janeiro de 2011, pessoalmente. À época, estes ocupavam, respectivamente, os cargos de deputado federal, deputada estadual, e deputado federal. É importante esclarecer que estas pessoas foram entrevistadas enquanto representantes de seus partidos no estado, e suas falas tomadas como posições públicas oficiais.

\section{Recrutamento e cotas}

A questão de recrutamento gerou muitas respostas vagas e evasivas, indicando que realmente não há estratégia clara para a incursão de novas pessoas nos partidos. É aparente que se espera que os interessados e interessadas busquem o partido por conta própria, algo que é congruente com as respostas coletadas no survey sobre o uso de um critério pessoal para a escolha partidária e com o que diz a literatura sobre partidos no Brasil.

O presidente do Partido dos Trabalhadores (PT) concentrou sua resposta em explicar a história do seu partido e seu enraizamento nos movimentos sociais e populares, indicando que existe uma associação "natural" entre pessoas da sociedade civil organizada e de classes socioeconômicas mais baixas com o partido, afirmando existir uma característica renovadora do partido e a liderança do ex-presidente Luís Inácio Lula da Silva e da presidenta Dilma Rousseff. Para a presidenta do Partido Popular Socialista (PPS), este ainda está ligado à herança de esquerda e o considera um partido de esquerda. Por isso atrai, sem necessidade de recrutar, pessoas jovens, trabalhadores e mulheres ao invés de “empresários". O presidente do Partido da Social Democracia Brasileira (PSDB), por sua vez, explicou que sua agremiação não tem enraizamento social, mas que os departamentos internos (de juventude, de mulheres e de terceira idade) são proativos na busca de pessoas que possam compor a base do partido.

Sobre a questão das cotas, todos admitiram que há dificuldades para o cumprimento da regra. Como era de se esperar, as opiniões divergiram bastante. O presidente do PSDB apontou para sua participação na Comissão de Reforma Política da Câmara de Deputados e explicou que acredita que a falta de mulheres na política é uma questão cultural e natural e que isso não pode ser resolvido com uma lei. O deputado explica seu posicionamento

“...a resposta solta assim fica um tanto simplista porque se você pegar curso de medicina, faz uma pesquisa evolução histórica recente da distribuição de vagas mulheres-homens, pega nos concursos de ministérios públicos e de juizes. Pode ser, é uma hipótese, que a baixa participação da mulher, desproporcional pro seu peso demográfico, seja uma opção da mulher. Não, não seja somente uma discriminação, uma exclusão. Às vezes a mulher, por caraterísticas próprias, pelo jeito de ser, esteja priorizando outras atividades tão importantes quanto". 
O presidente do PT e a presidenta do PPS, por outro lado, mobilizaram conceitos sobre exclusão estrutural da mulher. A presidenta do PPS foca no sucesso de seu partido em cumprir as cotas para vereadoras e em como quanto mais mulheres houver no partido, maior o incentivo. Estudos sobre a presença feminina na política têm pesquisado o fenômeno do sucesso local das mulheres (MIGUEL e QUEIROZ, 2006), e a presidenta do PPS também mobiliza esse conhecimento, que ela atribui ao ônus de uma campanha fora do município de origem. Ela também lembra da dificuldade em conciliar "o trabalho fora de casa, o trabalho em casa incluindo cuidar dos filhos e criações dos filhos com a atividade política". A presidenta do PPS também aponta para a exclusão histórica como fator sobre as mulheres conseguirem se ver como seres políticos.

O presidente do PT focou nas cotas internas do partido e explica que as mulheres têm mais dificuldade por causa da dupla e tripla jornada de trabalho. Para ele, o ideal seria uma reforma política com paridade no Congresso Nacional, incluindo a possibilidade de lista fechada ou lista flexível. Ele falou sobre reforma política de forma geral e mencionou financiamento público exclusivo ou limitado para contribuições privadas e fim das coligações proporcionais como essenciais para a melhora da qualidade da democracia brasileira.

Foi perguntado se os presidentes e presidenta dos partidos notaram alguma diferença de interesse em filiação e candidatura após a eleição da presidenta Rousseff. Para o presidente do PSDB, a eleição de Rousseff mostra como a inclusão é uma "não-questão". De acordo com ele, não houve críticas ou questionamentos sobre a capacidade de Rousseff ou de Marina Silva, comprovando que não há preconceito. A presidenta do PPS respondeu não ter havido uma procura maior, mas sente que a situação está mudando de forma geral na sociedade brasileira, com mais mulheres votando em mulheres e com a presidenta confirmando a capacidade da mulher de governar. O presidente do PT nota um crescimento gradual, independente da eleição de Rousseff, que ele atribui ao "acúmulo já histórico do nosso partido".

\section{Capacitação e participação no partido}

Um dos obstáculos enfrentados por brasileiras na política é a falta de capital cultural com relação ao mundo político. Araújo (2010) argumenta que as mulheres entram na política como um meio para um fim, enquanto homens têm como objetivo a entrada na política, desenvolvendo as habilidades e os relacionamentos necessários durante suas carreiras. Adentrar numa campanha e subsequente eleição é uma tarefa desconhecida para a maioria das pessoas e a exclusão estrutural e histórica das mulheres é um obstáculo a mais com relação a retórica e discursos, formação de relações, publicidade, entre outros fatores. Sobre esse aspecto, o presidente do PT afirma

\footnotetext{
"Portanto, as nossas candidaturas, não é candidaturas, como se diz na linguagem popular, laranjas. Porém, é um exercício que você tem que estar fazendo permanentemente. Aprovamos dez por cento do nosso recurso para a formação das mulheres, ou seja, fazer com que as nossas companheiras possam estar mais preparadas, então tem recurso pra formação, capacitação, né, tal”.
}

Presidente estadual PT

Ele também mencionou capacitação realizada todos os candidatos e candidatas para 2010. De acordo com a presidenta estadual, o PPS também possui capacitação, mistas e para mulheres. Ela aponta que as mulheres "são mais frágeis, tem mais dificuldade de fazer campanha, de financiar, então nós estabelecemos uma estrutura mínima de recursos". Em contraposição, a funcionária do PPS que passou os dados sobre as candidatas afirmou, em conversa informal, que a estrutura mínima foi definida, mas nunca implantada. Ao ser questionada sobre essa afirmação, a presidenta apenas afirmou que é difícil "fazer uma coisa mais coletiva". 


\begin{abstract}
"O [partido] trabalha com a questão da formação, nós temos cursos para os pré-candidatos, aí indistintamente, homens e mulheres. Mas a comissão de mulheres do partido também faz reuniões separadamente com as candidatas, para incentivar, mulher tem até dificuldade para falar em público, para a candidata isso é muito difícil, ela vai ter que falar, ela tem que comunicar, Então assim, num ambiente misto ela fica mais inibidas por essa exclusão histórica. Então também há reuniões separadas com as pré-candidatas. Em dezembro mesmo, aconteceu uma, lá na sede do partido, que era para que cada uma falasse um pouco da sua história, das suas propostas e que essa discussão fosse coletiva".
\end{abstract}

Presidenta estadual PPS

O presidente do PSDB não entrou em detalhes, apenas citou sobre cursos regionais que seriam feitos através do instituto do partido.

É importante notar que, avaliando o desempenho das candidaturas femininas, o presidente do PT se repetiu sobre a jornada de trabalho da mulher e o presidente do PSDB mencionou o desempenho de Manuela D'Ávila (PCdoB - RS) e de Margaret Thatcher (primeira-ministra do Reino Unido, 1979-1990). A presidenta do PPS repetiu que as mulheres obtêm sucesso localmente, mas somem quando se candidatam fora de suas cidades. De acordo com ela, falta estrutura e trajetória para impulsionar essas candidaturas.

Todos os três partidos possuem um departamento de mulheres. As entrevistas permitiram captar a função desse departamento para o presidente estadual do partido, como ele é visto pela pessoa responsável pelo partido no estado. No caso do PT, o presidente afirmou que a secretaria tem um papel de "criação de políticas e posicionamentos", além de apoiar e organizar as filiadas. Ele lembrou que o partido tinha acabado de passar resolução de cotas internas de 50\%. No PPS, a resposta foi mais vaga, afirmando que os departamentos existem, estaduais e nacionais, mas não aprofundou na função destes. De acordo com ela, são reuniões abertas também aos homens, o que leva a entender que pode haver uma integração maior ou que sejam reuniões informativas (ao invés de seminários e debates), para que os homens saibam sobre as questões das mulheres. $\mathrm{O}$ partido também tem cotas internas, de 30\%. O presidente do PSDB falou sobre como o departamento é muito ativo e tem tentado crescer no interior do estado. Sobre o assunto de cotas, ele afirma

\footnotetext{
"Não, não tem não. Mas, nós, por exemplo tomamos resolução, essa coisa do assento na executiva tanto o jovem, o sindical e [a] mulher. Pra além, representando institucionalmente, né? Que é um contrassenso, quer dizer, tem essa coisa mas assim, é... por que que não tem um PSDB [para] homem e tem um PSDB [para] mulher? Já é uma revelação, acho que uma contradição, né? [risos] Mas, é, cê precisa ter um, uma ferramenta para atacar esse problema".
}

Presidente estadual PSDB

Para a presidenta do PPS, as cotas internas criam certa tensão nas reuniões nacionais. O presidente do PT acredita que deve existir alguma tensão, mas que o partido é muito "politicamente correto" para que haja reclamações explícitas. Apesar de não ter cotas internas, o presidente do PSDB afirma que existe tensão, mas não por gênero: “Tem tensão é entre todos os membros".

\title{
Apoio partidário
}

As perguntas colocadas nesta seção das entrevistas estiveram relacionadas ao apoio financeiro de campanha e critérios utilizados, uso do Fundo Partidário, divisão do Horário de Propaganda Eleitoral Gratuita e critérios utilizados, entre outros tipos. 
Sobre o apoio financeiro, as respostas são consistentes com as informações coletadas no survey e aceitas pela literatura. O PSDB tende a não ajudar financeiramente e não tem critério quando o faz, podendo ser igualitário ou para o puxador de voto. Em geral, arrecadação e gasto são individuais, mas televisão e rádio são todos pagos pelo partido durante campanha. O PT auxilia com material, televisão e rádio e apoio jurídico. Tenta-se, afirma o presidente, garantir uma “estrutura mínima”. Existe, também, uma tentativa de pedir 10\% da arrecadação individual para ajudar os candidatos e candidatas com arrecadações menores, mas não há controle sobre doações para os indivíduos. A presidenta do PPS também fala sobre "estrutura mínima" e que isso é feito com material e com capacitação, mas que o partido não tem recursos próprios.

Todos afirmaram que o Fundo Partidário é usado para manutenção do partido e que o horário eleitoral para candidaturas proporcionais é também dividido igualmente. No entanto, a colocação, seja no começo ou ao final, no programa da tarde ou da noite, podem ser relevantes, e essa decisão pode ser mais discricionária. Nenhum dos presidentes fez menção a este aspecto do Horário Gratuito de Propaganda Eleitoral (HGPE). O presidente do PSDB afirma que "dá muita polêmica" tentar dividir sem ser de forma igualitária. O presidente do PT explica

\begin{abstract}
"Não, o [PT] em Minas nunca fez essa opção [de dividir desigualmente]. Quando têm programas, igual tá tendo agora, então, às vezes você, a eleição municipal tem estratégia, falar como o [PT], o modo de governar, isso é transmitido através de prefeitos, então, depende do momento político, do tempo e do momento, a gente decide a linha do programa. Agora, evidente, quando se trata de disputa eleitoral, todos falam".
\end{abstract}

Presidente estadual PT

\title{
4. Conclusão
}

A pesquisa apresentada buscou explorar a relação entre a inclusão das mulheres na política com o espectro ideológico "esquerda-direita". Baseando em estudos brasileiros e internacionais que mostram que existe uma certa "essência" para cada posicionamento (vanguarda, moderação, tradição), pode-se ver que cada posição no espectro tem uma relação relativamente estável com a questão da inclusão em termos do que faz parte da pauta e dos interesses partidários. A inclusão das mulheres na política é, retoricamente, universalmente aceita, mas os métodos pela qual fazer essa inclusão é o ponto de disputa. Nota-se que incorporação da agenda de inclusão feminina não significa uma aceitação da agenda feminista.

A hipótese que guiou o trabalho foi a que partidos de esquerda são mais abertos e receptivos à participação feminina, tendo mais mulheres filiadas e candidatas e sendo mais permeáveis à sua atuação. Para testar essa hipótese, uma metodologia quanti-quali foi utilizada, com um survey aplicado a candidatas à ALMG em 2010 e uma entrevista semiestruturada a três presidentes estaduais de partidos com diferentes posicionamentos ideológicos. Espera-se, portanto, contribuir para o debate, mas não responder a questão de forma definitiva.

As entrevistadas demonstraram que não existem fronteiras ideológicas entre elas na questão da inclusão ou mesmo na autodeclaração sobre feminismo. A maioria acredita na necessidade de medidas institucionais que favoreçam sua participação e acreditam ser o papel das instituições, o partido em particular, de apoiar as mulheres na política. Assim como encontrado por Lovenduski e Norris (2004, pp. 10-11), o apoio a medidas que garantam maior inserção e possiblidade de competir para mulheres independe da ideologia partidária professada por elas. Sendo assim, a inclusão feminina na política é um tema suprapartidário da perspectiva das mulheres filiadas e não segue, necessariamente, o posicionamento oficial do partido ou posicionamentos em outras questões.

Com relação ao cotidiano dentro do partido, as entrevistadas de partidos de esquerda demonstraram se- 
rem mais ativas e mais próximas ideologicamente de seus partidos; $60 \%$ delas afirmaram já terem tido cargos no partido. No entanto, $68 \%$ acreditam que não recebem a mesma atenção e respeito quando atuam, em comparação com os homens, uma proporção maior que as entrevistadas de centro ou de direita. Uma possibilidade é a criação de um incômodo maior: tomados individualmente, partidos de esquerda tendem a possuir mais mulheres que outros partidos, particularmente os de direita; as mulheres da esquerda ainda tendem a participar mais, como é o caso das mulheres entrevistadas aqui (DALHERUP, 2006). Portanto, é possível que os homens ainda não tenham aceitado essa participação e exista um backlash ${ }^{16}$ considerando o ambiente ainda masculinizado (ALLEN, 2013).

Os dados apresentados indicam que as mulheres têm dificuldades em conseguir apoio partidário independente da ideologia do partido. Enquanto a esquerda apresenta uma pequena preponderância na abertura de espaços partidários e no conhecimento sobre as causas da sub-representação feminina, seu apoio às mulheres em tempos de campanha não difere dos outros campo ideológicos, apesar da aparente presença de mulheres nos cargos dirigentes do partido, afirmada pelas entrevistadas, ou esforços para aumentar a presença das mulheres nesses cargos na forma de cotas internas.

A pesquisa qualitativa corroborou muitas proposições sobre a relação entre ideologia e inclusão feminina. Existe uma clara distinção entre as respostas do presidente do PT e da presidenta do PPS em comparação às do presidente do PSDB. Sustenta-se aqui que as respostas da presidenta do PPS tendem a ser mais progressistas na questão do apoio às candidatas do que a própria atuação do seu partido, pelo seu próprio posicionamento como feminista. O PPS possui cotas internas de $30 \%$, foi o partido que apresentou o maior número de candidatas na eleição estudada (segunda maior em porcentagem), possui um departamento feminino e, ao menos, discute a aplicação de uma estrutura mínima de apoio à candidata. Essas são ações inegavelmente importantes para o avanço das mulheres na política, ainda que tenham um efeito majoritariamente simbólico.

O presidente do PT falou sobre reforma política e seus possíveis efeitos para a inclusão das mulheres e sobre como essas reformas foram feitas no exterior. Considerando o posicionamento forte do partido com relação à reforma política, é compreensível que o presidente estadual tenha conhecimento sobre as possíveis consequências de uma reforma. Levando em consideração os estudos apresentados sobre a aproximação de partidos de esquerda e o feminismo, e a informação sobre a Secretaria de Mulheres do PT e sua atuação enquanto formuladora de posicionamentos para o partido, este discurso era esperado.

O presidente do PSDB tinha conhecimento sobre algumas chefes de Estado, citando Merkel, Bachelet e Thatcher, exemplo comuns de como a meritocracia "funciona bem" (MURRAY, 2014, p. 3). Existe a possibilidade que a posição dele não seja idêntica à tomada pelo partido, especialmente quando se considera que não há informação sobre como o departamento feminino do partido funciona. Enquanto representante máximo oficial do partido para o estado, é digno de nota que ele não soube informar sobre a atuação do departamento feminino.

Nessa linha, as três pessoas entrevistadas são os representantes estaduais de seus partidos e estavam sendo entrevistados nessa capacidade. Dessa forma, a interpretação de suas falas devem ser tomadas como posições oficiais. Considerando o conhecimento existente sobre os partidos, pode-se sugerir que os presidentes do PT e do PSDB foram mais congruentes em suas falas com relação à atuação de seus partidos.

Enquanto o discurso dos partidos diferencia fortemente, assim como ações como cotas internas, conclui-se que tanto no cotidiano partidário, mas especialmente em época de campanha, partidos de diferentes ideologias não oferecem maior apoio às candidatas de forma a avançar a inclusão das mulheres na política com mais mulheres eleitas. O sistema político brasileiro incentiva a atuação individual de cada político, reforçando um sistema desigual e neutralizando quaisquer interesses em medidas de equiparação.

\footnotetext{
${ }^{16}$ Backlash é um termo em inglês que significa uma reação oposta ao movimento, mas que se posiciona de forma neutra ou positiva. No caso do feminismo, é comum que o backlash argumente que o feminismo é a fonte dos problemas das mulheres. Ele também pode ser uma ação violenta
} ou de repressão ou também a marginalização de opiniões e ações feministas (WALBY, 1997). 


\section{Referências bibliográficas}

ALLEN, Peter. 2013. Gendered Candidate Emergence in Britain: Why are More Women Councillors Not Becoming MPs?. Politics, v. 33, n. 3, p. 147-159.

ARAÚJO, Clara. 2010. Rotas de ingresso, trajetórias e acesso das mulheres ao legislativo: um estudo comparado entre Brasil e Argentina. Revista Estudos Feministas, v. 18, n. 2, p. 567-584.

BERNAUER, J.; GIGER, N.; ROSSET, J. 2015. Mind the gap: Do proportional electoral systems foster a more equal representation of women and men, poor and rich? International Political Science Review, v. 36, n. 1, p. 78-98.

BOBBIO, Norberto. 1996. Left and Right. The Significance of a Political Distinction. Chicago: University of Chicago Press.

CARMineS, E. G.; ENSLEY, M. J.; WAGNER, M. W. 2012. Who Fits the Left-Right Divide? Partisan Polarization in the American Electorate. American Behavioral Scientist, v. 56, n. 12, p. 1631-1653.

CELIS, Karen; CHILDS, Sarah. 2012. The Substantive Representation of Women: What to Do with Conservative Claims? Political Studies, v. 60, n. 1, p. 213-225.

Centro Feminista de Estudos e Assessoria (CFEMEA). Como parlamentares pensam os direitos das mulheres? Pesquisa na Legislatura 2007- 2010 do Congresso Nacional. 2009. Disponível em: <http://www.observatoriodegenero.gov.br/menu/noticias/arquivos/pesquisa-cfemea-parlamentares>. Acesso em: 09 mar. 2016.

Centro de Estudos Legislativos (CEL-UFMG). Trajetórias, perfis e padrões de interação de legisladores estaduais em doze unidades da federação. Dados de 2005 e 2010.

Centro de Estudos Legislativos (CEL-UFMG). Representação política e qualidade da democracia: um estudo das elites parlamentares da América Latina. Dados de 2003 e 2007.

DAHLERUP, Drude. 2006. The Story of the Theory of Critical Mass. Politics \& Gender, v. 2, n. 04, p. 511-522.

DAHLERUP, Drude; FREIDENVALL, Lenita. 2011. Gender Quotas in Politics - A Constitutional Challenge. In: WILLIAMS, Susan Hoffman (Org.). Constituting equality: gender equality and comparative constitutional law. 1. paperback ed. Cambridge: Cambridge Univ. Press.

DWORKIN, Ronald. 2005. Uma Questão De Princípio. Edição: 2a . São Paulo: Martins Fontes - Selo Martins.

GUNTHER, Richard; HSIN-CHI, Kuan. 2007. "Value cleavages and partisan conflict”. In: GUNTHER, R.; MONTERO, J. R.; PUHLE, Hans-Jürgen., eds. Democracy, Intermediation, and Voting on Four Continents. Oxford: Oxford University Press.

HUGHES, Melanie e PAXTON, Pamela. 2008. Continuous Change, Episodes, and Critical Periods: A Framework for Understanding Women's Political Representation over Time. Politics \& Gender, v. 4, n. 2.

INGLEHART, Ronald e NORRIS, Pippa. 2003. Rising tide: gender equality and cultural change around the world. . Cambridge, UK ; New York: Cambridge University Press.

KYMILICKA, Will. Multicultural citizenship. 1995. A liberal theory of minority rights. Oxford: Claredon Press.

LAWLESS, Jennifer L.; FOX, Richard. 2010. It Still Takes a Candidate - Why Women Don 't Run for Office. New York: Cambridge University Press. 
LEONI, Eduardo. Ideologia, Democracia e Comportamento Parlamentar: A Câmara dos Deputados (19911998). 2002. DADOS - Revista de Ciências Sociais, Rio de Janeiro, Vol. 45, nº 3.

LOVENDUSKI, Joni e NORRIS, Pippa. 2003. Westminster Women: the Politics of Presence. Political Studies, v. 51, n. 1, p. 84-102.

MELO, Carlos Ranulfo Félix. 2010. Eleições presidenciais, jogos aninhados e sistema partidário no Brasil. Revista Brasileira de Ciência Política, Brasília, no 4, pp. 13-41, julho-dezembro.

MIGUEL, Luís Felipe. 2003. Capital político e carreira eleitoral: algumas variáveis na eleição para o congresso brasileiro. Revista de Sociologia e Política, n. 20, p. 115-134.

MIGUEL, Luis Felipe e QUEIROZ, Cristina Monteiro de. 2006. Diferenças regionais e o êxito relativo de mulheres em eleições municipais no Brasil. Estudos Feministas, v. 14, n. 2, p. 363.

MURRAY, Rainbow. Quotas for men: Reframing Gender Quotas as a Means of Improving Representation for All. 2014. American Political Science Review, v. 108, n. 3, p. 520-532.

PHILLIPS, Anne. 1995. The politics of presence. Oxford : New York: Clarendon Press ; Oxford University Press. (Oxford political theory).

PHILLIPS, Anne. 2004. Defending Equality of Outcome. Journal of Political Philosophy, v. 12, n. 1, p. 1-19.

POWER, Timothy e ZUCCO, Cesar. 2009. Estimating Ideology of Brazilian Legislative Parties, 19902005: A Research Communication. Latin American Research Review, Volume 44, $\mathrm{n}^{\circ} 1$.

POWER, Timothy e ZUCCO, Cesar. 2011. O Congresso por ele mesmo - autopercepções da classe politica brasileira". Belo Horizonte: Editora UFMG.

SAMUELS, David. 1997. Determinantes do Voto Partidário em Sistemas Eleitorais Centrados no Candidato: Evidências sobre o Brasil. Dados, vol. 40 n 3 .

SANTOS, Fabiano. 2011. Brazilian Democracy and the Power of "Old" Theories of Party Competition. Brazilian Political Science Review, v. 2, n. 1, p. 57-76.

SCHOLZ, Evi; ZUELL, Cornelia. 2012. Item non-response in open-ended questions: Who does not answer on the meaning of left and right? Social Science Research, v. 41, n. 6, p. 1415-1428.

SKINNER, Quentin. 1999. Liberdade antes do liberalismo. São Paulo: Editora UNESP.

TAROUCO, Gabriela da Silva e MADEIRA, Rafael Machado. 2013. Partidos, programas e o debate sobre esquerda e direita no Brasil. Revista de Sociologia e Política, v. 21, n. 45, p. 149-165.

VEIGA, Luciana Fernandes. 2007. Os partidos brasileiros na perspectiva dos eleitores: mudanças e continuidades na identificação partidária e na avaliação das principais legendas após 2002. Opinião Pública, v. 13, n. 2, p. 340-365.

WALZER, Michael. 2004. Politics and Passion: Toward a more egalitarian liberalism. New Hampshire: Yale University Press.

ZUCCO, Cesar. 2009. Esquerda, Direita e Governo: A ideologia dos partidos politicos brasileiros. Preparado para o Seminário "Legislator Views of Brazilian Governance", Universidade de Oxford, Setembro. ZUCCO, Cesar e LAUDERDALE, Benjamin E. 2011. Distinguishing Between Influences on Brazilian Legislative Behavior: Brazilian Legislative Behavior. Legislative Studies Quarterly, v. 36, n. 3, p. 363-396, agosto.

WALBY, Sylvia. 1997. Gender transformations. Londres: Routledge.

(Footnotes) 
${ }^{1}$ É importante notar que, observando todos os dados recolhidos para a pesquisa original, duas variáveis se apresentaram relevantes para sucesso eleitoral: financiamento de campanha e ter tido cargo eletivo anteriormente. A pesquisa completa faz parte da dissertação “A presença feminina nos espaços legislativos: um estudo das eleições de 2010 para a Assembleia Legislativa de Minas Gerais" (GOMES, 2012). 